\title{
Establishment of an expression platform of OATP1B1 388GG and 521CC genetic polymorphism and the therapeutic effect of tamoxifen in MCF-7 cells
}

\author{
ZHICHEN PU $^{1 *}$, XUEFENG ZHANG $^{1 *}$, QUN CHEN $^{2}$, XIAOLONG YUAN $^{1}$ and HAITANG XIE ${ }^{1}$ \\ ${ }^{1}$ Department of Clinical Pharmacy, Yijishan Hospital of Wannan Medical College, \\ Anhui Province Center for Drug Clinical Evaluation; ${ }^{2}$ Department of Pharmacy, \\ Wuhu Chinese Medicine Hospital, Wuhu, Anhui 241001, P.R. China
}

Received October 28, 2014; Accepted February 10, 2015

DOI: $10.3892 /$ or.2015.3864

\begin{abstract}
The present study was designed to evaluate the gene polymorphisms of organic anion transporting polypeptide 1B1 (OATP1B1) in predicting the therapeutic efficacy of tamoxifen (TAM) for MCF-7. Established plasmids OATP1Bl wild-type $388 \mathrm{GG}$ and $521 \mathrm{CC}$ were transfected into MCF-7 cells and used to determine whether the gene polymorphisms affected the therapeutic efficacy of TAM for MCF-7. The established plasmids pcDNA3.1(-)-OATP1B1 wild-type 388GG and $521 \mathrm{CC}$ were digested by restriction enzymes and analyzed by gene sequencing. The gene polymorphisms of OATP1B1 in MCF-7 breast cancer cells were examined by RT-PCR and western blot analysis. The results showed that the mutations of OATP1B1 388GG and 521CC led to a decrease of the inhibition and apoptotic rates of MCF-7 cells, albeit not significantly compared to the OATP1B1 group. The $G_{0} / G_{1}$ phase length ratio was reduced, and the $S$ and $G_{2} M$ phases were increased in the OATP1B1 $388 \mathrm{GG}$ and $521 \mathrm{CC}$ groups, although not significantly compared to the OATP1B1 group. The mutations of OATP1B1 388GG and 521CC inhibited the activity of OATP1B1 protein, restrained the turnover capacity of OATP1B1 and reduced the entrance of TAM into MCF-7 cells, resulting in weakened efficacy of TAM in the treatment of breast cancer.
\end{abstract}

\section{Introduction}

Breast cancer continues to be the most common type of cancer diagnosed among women in China, and it was estimated that

Correspondence to: Professor Haitang Xie, Department of Clinical Pharmacy, Yijishan Hospital of Wannan Medical College, Anhui Province Center for Drug Clinical Evaluation, Wuhu, Anhui 241001, P.R. China

E-mail: xiehaitang@sina.com

*Contributed equally

Key words: tamoxifen, breast cancer, OATP1B1, OATP1B1 388GG, OATP1B1 521CC there were $\sim 232,340$ new cases of invasive breast cancer in 2013 (1). The American Cancer Society projected 39,620 breast cancer-associated mortalities in 2013 (2). In the past three decades, breast cancer has been the second leading cause of cancer death after lung cancer (3). However, breast cancer is a complex disease entity with different biological characteristics and clinical behavior. Many studies have shown that there are no treatment guidelines for triple-negative breast cancer.

Adjuvant endocrine therapy is an important method used for the comprehensive treatment of breast cancer (4). Chemotherapy for breast cancer is closely associated with hormone levels. Tamoxifen (TAM) is non-synthetic cholesterol antiestrogen, which is the basic drug utilized in adjuvant endocrine therapy for breast cancer. TAM is widely used to treat breast cancer patients (5). However, the differences in the gene polymorphism of patients who are administered the drug may lead to individual differences regarding efficacy and toxicity (6). Genetic factors play an important role in these differences.

Organic anion transporting polypeptide 1B1 (OATP1B1) is a type of intake body, distributed in multiple human organs and particularly distributed in specific organs (7). It belongs to the superfamily of solute uptake, of which the encoding genes are known as the SLCOIBI gene collectively. In the Chinese population, mutation frequencies of OATP1B1 388A $>\mathrm{G}$ and OATP1B1 521T $>\mathrm{C}$ are 73.4 and $14.0 \%$, respectively, which are similar to those of the Japanese population $(8,9)$. The incidence rate of OATP1B1 521T $>\mathrm{C}$ is $16 \%$ in Asians and $18 \%$ in Caucasians, thus this incidence rate is varied based on ethnicity (10). Studies have shown that in African-Americans, the mutation rate of OATP1B1 388G is 2.5-fold that of Europeans and Americans, with the mutation rate of OATP1B1 $521 \mathrm{C}$ being higher among the Finnish population. The mutations of OATP1B1*15 (388G and 521C) is $43.4 \%$ in the Japanese population simultaneously. However, the incidence rate of OATP1B1*15 is $14 \%$ in Caucasians (11).

The majority of current studies concerning the genetic polymorphism of OATPIB1 have focused on statin drugs, which enter the liver cells to exert an inhibitory effect on HMG-CoA reductase. Therefore, OATP1B1 is important in most internalization processes of statin drugs into hepatocytes (12). 
Recent findings have shown that the genetic polymorphism of OATPIB1 affects the pharmacokinetic process of irinotecan in cancer patients significantly, including OATP1B1*la, OATP1B1*lb, OATP1B1*5 and OATP1B1*15 $(13,14)$.

There were no significant effects on simvastatin pharmacokinetics by SLCO1B1 388A $>$ G, SLCO1B1 521T>C, SLCO1B1 11187G >A, SLCO1B1 571T>C and SLCO1B1 $597 \mathrm{C}>\mathrm{T}$. Ritonavir intracellular concentrations were associated with OATP1B1 521T $>$ C polymorphism (15). Previous results suggest that the gene mutation of OATP1B1 521T $>C$ influences the transport of rosuvastatin (16). However, no association between the OATP1B1 521T $>C$ polymorphism and the cholesterol synthesis response and rosuvastatin plasma concentration has been identified (17). OATP1B1 388A $>\mathrm{G}$ and 521T $>\mathrm{C}$ have been shown to lead to altered pharmacokinetics of pravastatin. The pharmacokinetics of irinotecan, estrone-3-sulfate and estradiol-17 $\beta$-glucuronide also affect OATP1B1 388A $>\mathrm{G}$ and 521T $>\mathrm{C}$, although without statistical significance (18).

In the present study, we found that the specific mutation of OATP1Bl significantly reduced the uptake activity of OATP1Bl protein, which may affect the internalization of many endogenous substances and drug uptake into hepatocytes and significantly influence the metabolism and efficacy of many drugs. OATP1Bl also influences the adverse reactions of some drugs and the interaction between drugs. A gene polymorphism expression platform of OATP1B1 388GG and 521CC was also established and utilized to determine whether OATP1B1 388GG and OATP1B1 521CC gene polymorphisms can affect TAM treatment of breast cancer in vitro.

\section{Materials and methods}

Total RNA extraction. Approximately $100 \mathrm{mg}$ tissue was ground into a powder in liquid nitrogen, and moderate RNAiso Plus (Qiagen, Hilden, Germany) was added for 5-10 min at room temperature. The supernatant was collected by centrifugation at $12,000 \mathrm{rpm}$ for $5 \mathrm{~min}$ at $4^{\circ} \mathrm{C}$ followed by the addition of chloroform. Miscible liquids were agitated and placed for 5-10 min at room temperature. The miscible liquids were collected by centrifugation at $12,000 \mathrm{rpm}$ for $15 \mathrm{~min}$ at $4^{\circ} \mathrm{C}$. The supernatant was absorbed into the new centrifuge tube. The isopropanol, which was the same volume as that of the supernatant, was added to the centrifuge tube, and placed for $10 \mathrm{~min}$ at room temperature. The liquid was centrifuged at $12,000 \mathrm{rpm}$ for $10 \mathrm{~min}$ to obtain a sediment. One millimeter $75 \%$ ethyl alcohol was added to the centrifuge tube. The liquid was centrifuged at $12,000 \mathrm{rpm}$ for $5 \mathrm{~min}$ to obtain sediment again. The sediment obtained was dried at room temperature, and then treated in 20-100 $\mu$ l DEPC- $\mathrm{H}_{2} \mathrm{O}$. Total RNA was maintained at $-80^{\circ} \mathrm{C}$.

cDNA synthesis. Total RNA $(1 \mu \mathrm{l}), 1 \mu \mathrm{l} 0.5 \mu \mathrm{g} / \mu \mathrm{l}$ oligo(dT) and $10 \mu \mathrm{l}$ DEPC- $\mathrm{H}_{2} \mathrm{O}$ was mixed, subjected to PCR at $70^{\circ} \mathrm{C}$ for $5 \mathrm{~min}$ and cooled rapidly on ice. Four microliters $5 \mathrm{X}$ reaction buffer, $1 \mu 120 \mathrm{U} / \mu 1 \mathrm{RNA}$ enzyme inhibitors and $2 \mu 110 \mathrm{mmol} / 1$ dNTP were dissolved in miscible liquids and subjected to PCR at $37^{\circ} \mathrm{C}$ for $5 \mathrm{~min}$. One microliter $200 \mathrm{U} / \mu 1$ reverse transcriptase was added and the mixture was subjected to PCR. Cycling
Table I. The site-directed mutagenesis primers of OATP1B1 388GG and 521CC.

\begin{tabular}{ll}
$\begin{array}{l}\text { Name of } \\
\text { primer }\end{array}$ & \multicolumn{1}{c}{$5^{\prime} \rightarrow 3^{\prime}$} \\
\hline $388 \mathrm{GG}$ & GAAAGAAACTAATATCGATTCATCAGAAAATTC \\
$388 \mathrm{GG}$ & GATTATAGGTAAGTAGTCTTTTAAGTTGTAGC \\
$521 \mathrm{CC}$ & ACATGTGGATATATGCGTTCATGGGTAATAT \\
$521 \mathrm{CC}$ & TATTACCCATGAACCCATATATCCACATG
\end{tabular}

conditions used were: $42^{\circ} \mathrm{C}$ for $60 \mathrm{~min}$ and $70^{\circ} \mathrm{C}$ for $10 \mathrm{~min}$. cDNA synthesis was maintained at $-80^{\circ} \mathrm{C}$.

DNA extraction. The primers were designed according to gene coding sequence (CDS) of OATP1B1 in GenBank. KpnI and NotI restriction sites were subsequently inserted. The primers used were: forward: 5'-TTAGCGGCCGCATGGACCAAA ATCAACATT-3' and reverse, 5'-GCCGGTACCTTAACA ATGTGTTTCACTATCTG-3'.

cDNA $(2-4 \mu \mathrm{l}), 2 \mu \mathrm{l}$ sense primer $(10 \mathrm{pM}), 2 \mu \mathrm{l}$ reverse primer (10 pM), $4 \mu \mathrm{l}$ dNTP ( $2 \mathrm{mM}), 5 \mu \mathrm{l}$ 10X PCR buffer, $1 \mu \mathrm{l}$ Taq DNA Polymerase (Takara, Otsu, Japan) and moderate DEPC- $\mathrm{H}_{2} \mathrm{O}$ were mixed in the centrifuge tube, and the total volume was $50 \mu \mathrm{l}$. Cycling conditions used were: $94^{\circ} \mathrm{C}$ for $10 \mathrm{~min}$ followed by 40 cycles at $95^{\circ} \mathrm{C}$ for $30 \mathrm{sec}, 58^{\circ} \mathrm{C}$ for $90 \mathrm{sec}$ and $72^{\circ} \mathrm{C}$ for $30 \mathrm{sec}$, and then $72^{\circ} \mathrm{C}$ for $7 \mathrm{~min}$. DNA was kept at $-80^{\circ} \mathrm{C}$. DNA OATP1B1 was analyzed by electrophoresis of 0.5 or $1 \%$ agarose gel followed by gene sequencing.

Construction of plasmids. KpnI and NotI, DNA OATP1B1 and pcDNA3.1(-) plasmid were mixed at $37^{\circ} \mathrm{C}$ for $1-4 \mathrm{~h}$ and at $70^{\circ} \mathrm{C}$ for $10 \mathrm{~min}$ according to the manufacturer's instructions (Takara). T4 DNA ligase (Takara) was then added to the mixture at $16^{\circ} \mathrm{C}$ for $1-4 \mathrm{~h}$ and at $70^{\circ} \mathrm{C}$ for $10 \mathrm{~min}$. pcDNA3.1(-)OATP1B1 plasmid was identified by restriction enzyme digestion (KpnI and NotI), and analyzed by electrophoresis of $0.5 \%$ agarose gel and gene sequencing.

Site-directed mutagenesis of OATP1B1 388GG and 521CC. The site-directed mutagenesis primers of OATP1B1 388GG and OATP1B1 521CC were designed according to OATP1B1 gene CDS in GenBank (Table I). The plasmid of $1 \mu 1$ pcDNA3.1 (-)-OATP1B1, $5 \mu \mathrm{l}$ 10X Pfu polymerase buffer $\left(\mathrm{Mg}^{2+}\right), 2 \mu \mathrm{l}$ sense primer $(10 \mathrm{pM}), 2 \mu \mathrm{l}$ reverse primer $(10 \mathrm{pM}), 1 \mu \mathrm{l} \mathrm{Pfu}$ DNA polymerase (5 U) (Promega, Shanghai, China), and $39 \mu 1$ DEPC- $\mathrm{H}_{2} \mathrm{O}$ were mixed and subjected to PCR. Cycling conditions were as follows: $95^{\circ} \mathrm{C}$ for 4 min followed by 25 cycles at $95^{\circ} \mathrm{C}$ for $60 \mathrm{sec}, 62^{\circ} \mathrm{C}$ for $45 \mathrm{sec}$ and $72^{\circ} \mathrm{C}$ for $30 \mathrm{sec}$, and then $72^{\circ} \mathrm{C}$ for $7 \mathrm{~min}$. PCR amplification products were digested with the restriction endonuclease $\mathrm{Cla}$ (Promega) at $37^{\circ} \mathrm{C}$ for 1-3 $\mathrm{h}$. The plasmids were maintained at $-80^{\circ} \mathrm{C}$. The plasmids were separated using 0.5 or $1 \%$ agarose gel followed by gene sequencing.

Plasmid transfection. The plasmids were constructed and transfected into MCF-7 cells using Lipofectamine 2000 (Invitrogen) according to the manufacturer's instructions in a 
humidified atmosphere at $37^{\circ} \mathrm{C}$ with $5 \% \mathrm{CO}_{2}$. After $6 \mathrm{~h}$, the transfection medium was replaced with Dulbecco's modified Eagle's medium (DMEM) containing 10\% fetal bovine serum (FBS) without antibiotic in a humidified atmosphere at $37^{\circ} \mathrm{C}$ with $5 \% \mathrm{CO}_{2}$. The OATP1B1 gene polymorphisms were examined in MCF-7 cell lines by RT-PCR and western blot assay.

Cell culture. MCF-7 human breast cancer cells were obtained from the Shanghai Institute of Cell Biology in the Chinese Academy of Sciences for the present study. MCF-7 cells were maintained in DMEM containing 10\% FBS supplemented with $100 \mathrm{U}$ penicillin/streptomycin in a humidified atmosphere at $37^{\circ} \mathrm{C}$ with $5 \% \mathrm{CO}_{2}$.

Experiments. The experiment was divided into six groups: A group was MCF-7; B group was MCF-7 with TAM $(10 \mu \mathrm{M})$; $\mathrm{C}$ group was MCF-7 transfected with pcDNA3.1(-) plasmid and provided with TAM $(10 \mu \mathrm{M})$; D group was MCF-7 transfected with pcDNA3.1(-)-OATP1B1 plasmid and provided with TAM $(10 \mu \mathrm{M})$; E group was MCF-7 transfected with pcDNA3.1(-)OATP1B1 388GG plasmids and provided with TAM $(10 \mu \mathrm{M})$; and F group was MCF-7 transfected with pcDNA3.1(-)OATP1B1 521CC plasmids and provided with TAM $(10 \mu \mathrm{M})$.

MCF-7 cell proliferation assay. MCF-7 cell proliferation was examined using the colorimetric assay using 3-(4,5-dimethylthiazol-2-yl)-2,5-diphenyltetrazolium bromide (MTT) assays. Cells were plated at $2.5-5 \times 10^{5}$ cells/well in a 96-well plate and incubated for $24 \mathrm{~h}$. The plasmids were transfected into MCF-7 cells. The cells were treated with TAM solutions at concentrations of $10 \mu \mathrm{M}$ for 24 and $48 \mathrm{~h}$. Phosphate-buffered saline (PBS; pH 7.4) alone was used as the vehicle-group. TAM was dissolved in PBS and was used as treat-groups. For the MTT assay, the vehicle- and treat-groups were incubated with $150 \mu \mathrm{l}$ MTT for $4 \mathrm{~h}$ at $37^{\circ} \mathrm{C}$. The medium was extracted from the plates. The plates were incubated with $100 \mu$ l dimethyl sulfoxide for $10 \mathrm{~min}$ at room temperature and agitated. The optic density was determined using an ELISA reader at $540 \mathrm{~nm}$.

Quantification of apoptotic cells by flow cytometry. Apoptotic cells were measured by flow cytometry (BD Biosciences, San Diego, CA, USA). The cells were stained using an Annexin V-FITC Apoptosis Detection kit according to the manufacturer's instructions. Briefly, MCF-7 cells $\left(5.0 \times 10^{5}\right.$ cells/well) were plated in 6-well plates and incubated for $24 \mathrm{~h}$. The plasmids were subsequently transfected into MCF-7 cells. The cells were treated with TAM solutions at concentrations of $10 \mu \mathrm{M}$ for 24 and $48 \mathrm{~h}$. PBS (pH 7.4) alone was used as the vehicle-group. TAM was dissolved in PBS and was used as treat-groups. For the apoptotic cell analysis, the cells of the vehicle- and treat-groups were trypsinized without ethylenediaminetetraacetic acid (EDTA) and centrifuged at 2,000 x g for $5 \mathrm{~min}$. The cells were collected, washed in PBS (pH 7.4), and centrifuged at 2,000 $\mathrm{x}$ g for $5 \mathrm{~min}$. The cell samples were suspended with $500 \mu 1$ combined buffer solution. Then, $5 \mu \mathrm{l}$ fluorescein isothiocyanate (FITC)-Annexin V and $10 \mu 1$ propidium iodide (PI) were added into the cell samples and incubated for 5-15 min at room temperature in the dark. Apoptotic cells were analyzed by flow cytometry (BD Biosciences).
Cell cycle analysis by flow cytometry. Cell cycle analysis of MCF-7 cells was examined using the standard PI method by flow cytometry (BD Biosciences). Briefly, MCF-7 cells $\left(5.0 \times 10^{5}\right.$ cells/well) were plated in 6-well plates and incubated for $24 \mathrm{~h}$. The plasmids were subsequently transfected into MCF-7 cells. The cells were treated with TAM solutions at concentrations of $10 \mu \mathrm{M}$ for 24 and $48 \mathrm{~h}$. PBS (pH 7.4) alone was used as the vehicle-group. TAM was dissolved in PBS and was used as treat-groups. For the cell cycle analysis, the cells of the vehicle- and treat-groups were trypsinized without EDTA and centrifuged at $2,000 \mathrm{xg}$ for $5 \mathrm{~min}$. The cells were harvested, washed in PBS (pH 7.4) and fixed in 70\% with ice-cold ethanol at $0-4^{\circ} \mathrm{C}$ overnight. The cells were collected and centrifuged at 2,000 $\mathrm{xg}$ for $5 \mathrm{~min}$ and the supernatant was removed. The cell pellet was resuspended and washed in PBS (pH 7.4). The cell solution was transferred to a flow tube, and incubated with $10 \mathrm{ml}$ of RNase A $(10 \mathrm{mg} / \mathrm{ml})$ for $1 \mathrm{~h}$ at $37^{\circ} \mathrm{C}$. The cell samples were incubated with $50 \mathrm{ml}$ of PI $(250 \mathrm{mg} / \mathrm{ml})$ for $30 \mathrm{~min}$ in the dark at $0-4^{\circ} \mathrm{C}$. The cell cycle proliferation index was subsequently calculated using the formula: $\mathrm{PI}=\left(\mathrm{G}_{2} / \mathrm{M}+\mathrm{S}\right) /$ $\left(\mathrm{G}_{0} / \mathrm{G}_{1}+\mathrm{S}+\mathrm{G}_{2} / \mathrm{M}\right) \times 100 \%$. The cell cycle distribution was analyzed by flow cytometry (BD Biosciences).

Statistical analysis. The experiments were repeated at least three times. Data are presented as the mean \pm SEM. The differences between means were analyzed using the two-tailed Student's t-test. Statistical analyses were performed using SPSS 17.0 software. Differences with $\mathrm{P}<0.05$ were considered to indicate a statistically significant result.

\section{Results}

DNA fragmentation of OATP1B1. DNA fragmentation of OATP1B1 was analyzed by electrophoresis of $1 \%$ agarose gel, which showed that the amplified gene fragment was 2,096 bp (Fig. 1A). The DNA fragmentation of OATP1B1 was analyzed by gene sequencing, which showed that the amplified gene fragment identified the 388 site as A, and the 521 site as T (Fig. 1B and C).

Restriction enzyme and gene sequence of pcDNA3.1(-)OATP1B1. The established plasmids of pcDNA3.1(-)-OATP1B1 were digested by restriction enzymes (KpnI and NotI). The products were analyzed by electrophoresis of $0.5 \%$ agarose gel, which showed that pcDNA3.1(-) was $5.4 \mathrm{~kb}$, while the OATP1B1 fragment was 2,096 bp (Fig. 2A). Gel extraction of the OATP1B1 fragment was performed and the fragment was analyzed by gene sequencing, which showed that the amplified gene fragment identified the 388 site as A, and the 521 site as T (Fig. 2B and C).

Restriction enzymes and gene sequencing of pcDNA3.1(-)OATP1B1 $388 G G$ and 521 CC. The established plasmids of pcDNA3.1(-)-OATP1B1 388GG were digested by restriction enzymes, KpnI and NotI. These products were analyzed by electrophoresis of $0.5 \%$ agarose gel, which showed that pcDNA3.1(-) was $5.4 \mathrm{~kb}$, and the OATP1B1 fragment was 2,096 bp (Fig. 3A). The OATP1B1 fragment was extracted using gel extraction and analyzed by gene sequencing. The amplified gene fragment identified at the 388 site was $\mathrm{G}$ (Fig. 3B). 

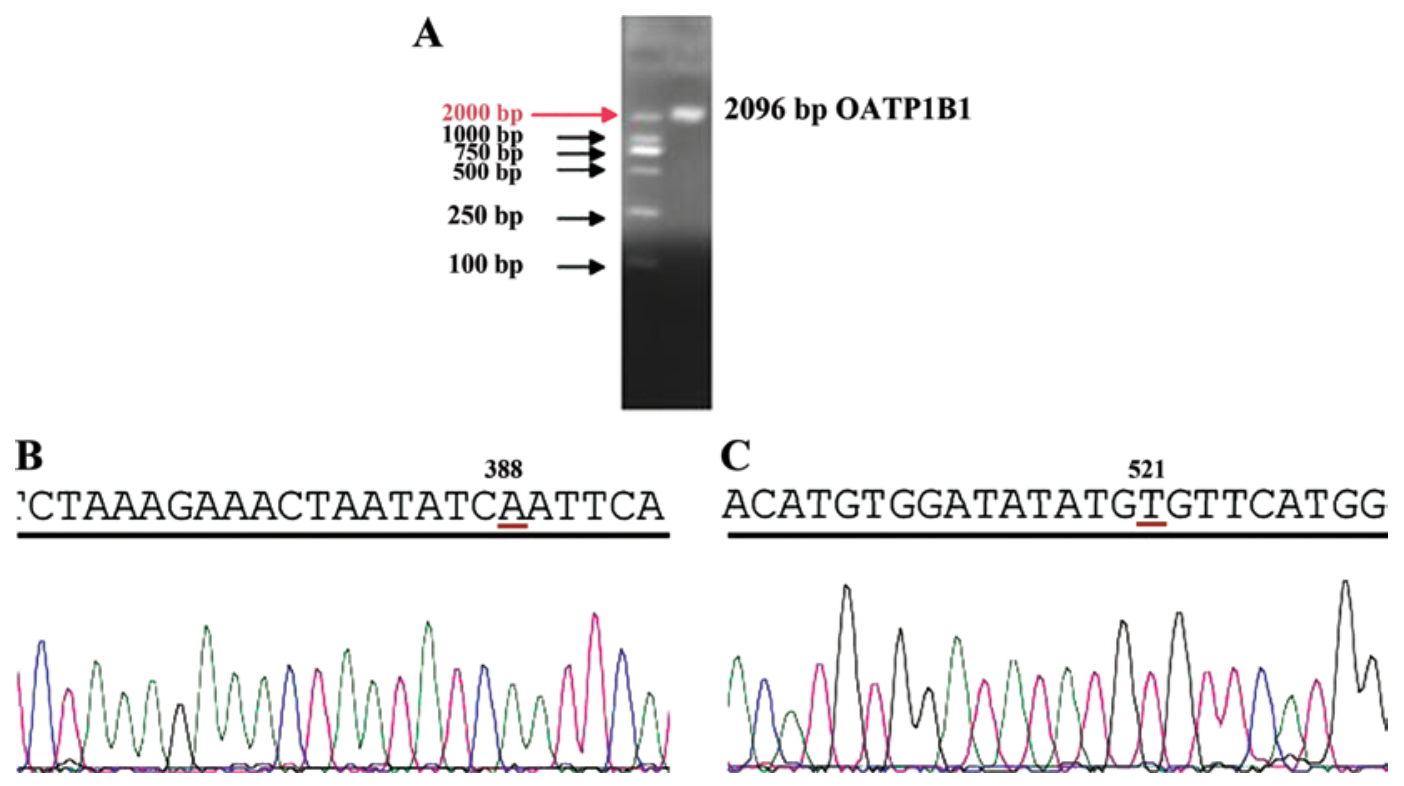

Figure 1. DNA fragmentation of OATP1B1 was analyzed by electrophoresis of $1 \%$ agarose gel: (A) left of image is DNA marker and right of image is the OATP1B1 fragment. DNA fragmentation of OATP1B1 was analyzed by gene sequencing: (B) OATP1B1 388 site was A and (C) OATP1B1 521 site was T.


Figure 2. Restriction enzyme and gene sequence of pcDNA3.1(-)-OATP1B1. The established plasmids of pcDNA3.1(-)-OATP1B1 were digested by restriction enzymes: (A) left of image is pcDNA3.1(-) and right of image is DNA marker. The established plasmids of pcDNA3.1(-)-OATP1B1 were analyzed by gene sequencing: (B) OATP1B1 388 site was A and (C) OATP1B1 521 site was T.

The established plasmids of pcDNA3.1(-)-OATP1B1 521CC were digested by restriction enzymes, $K p n I$ and NotI. The products were analyzed by electrophoresis of $0.5 \%$ agarose gel, which showed that pcDNA3.1(-) was $5.4 \mathrm{~kb}$, and the OATP1B1 fragment was 2,096 bp (Fig. 3C). The OATP1B1 fragment was extracted using gel extraction and was analyzed by gene sequencing, which showed that the amplified gene fragment identified at the 521 site was C (Fig. 3D).

Cataphoresis of plasmid transfection. RNA was extracted from the transfection of MCF-7 cells of each group, and PCR was used to amplify double-stranded DNA. The electrophoretic analysis was performed on the product using $1 \%$ agarose gel, which showed that the plasmid was successfully expressed (Fig. 4).

Western blotting of plasmid transfection. The OATP1B1 gene polymorphisms in MCF-7 cell lines were examined by western blot assay. A was MCF-7 cell, B was pcDNA3.1(-) was transfected into MCF-7 cell, C was pcDNA3.1(-)-OATP1B1 was transfected into MCF-7 cell, D was pcDNA3.1(-)OATP1B1 388GG was transfected into MCF-7 cell, E was 

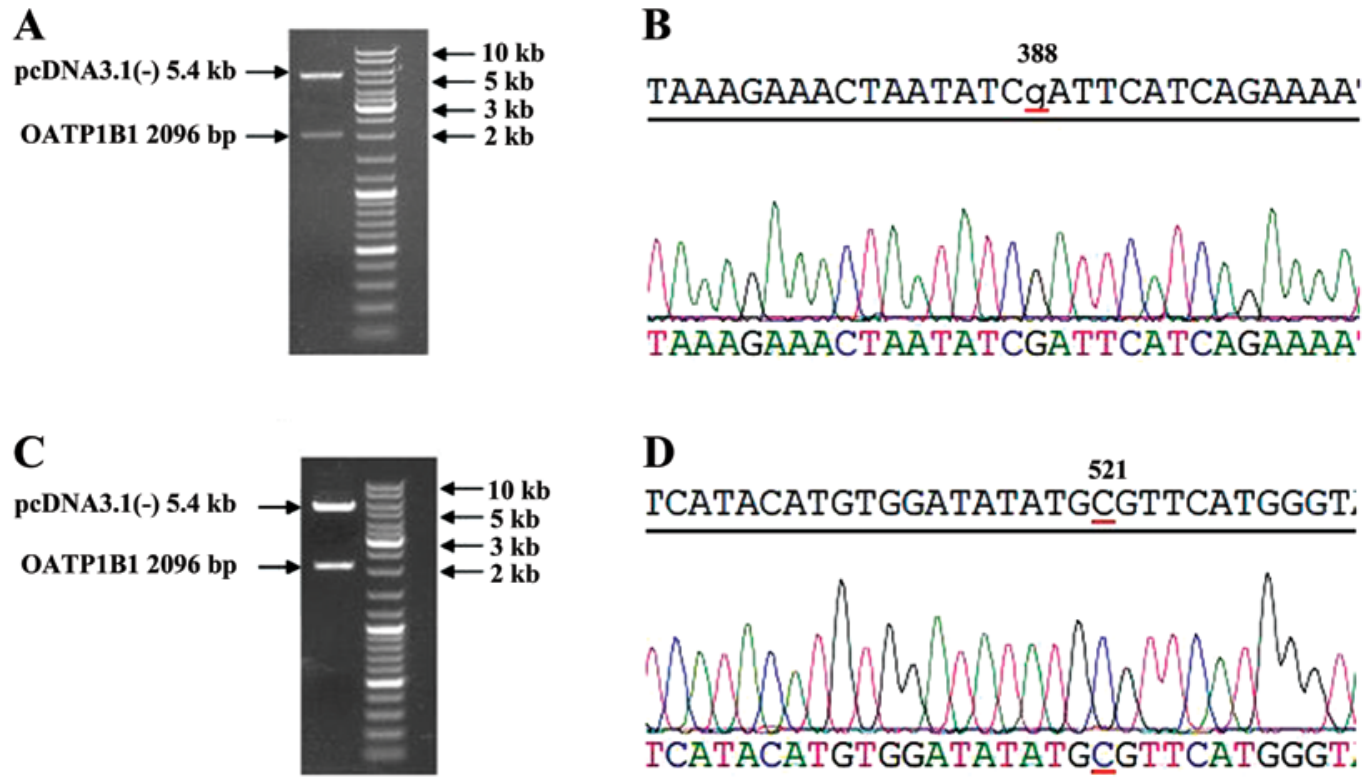

Figure 3. Restriction enzyme and gene sequence of pcDNA3.1(-)-OATP1B1 388GG and 521 CC. The established plasmids of pcDNA3.1(-)-OATP1B1 388GG were digested by restriction enzymes: (A) left of image is pcDNA3.1(-) 388GG and right of image is DNA marker. The established plasmids of pcDNA3.1 (-)-OATP1B1 388GG were analyzed by gene sequencing: (B) OATP1B1 388 site was G. (C) The established plasmids of pcDNA3.1(-)-OATP1B1 521CC were digested by restriction enzymes: left of the image is pcDNA3.1(-) 521CC and right of the image is DNA marker. The established plasmids of pcDNA3.1(-)OATP1B1 521CC were analyzed by gene sequencing: (D) OATP1B1 521 site was C.

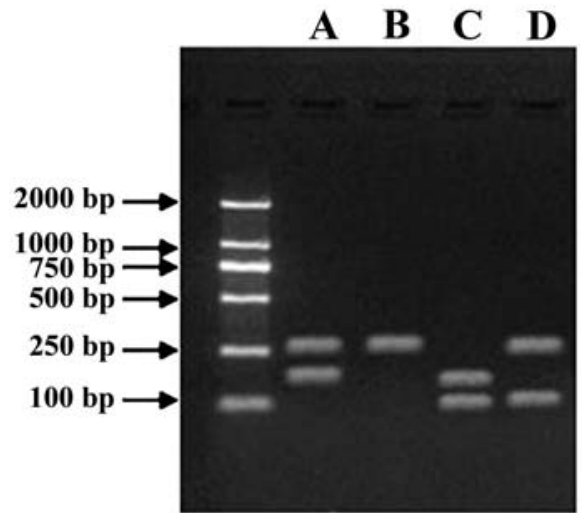

Figure 4. Cataphoresis of plasmid transfection. The OATP1B1 gene polymorphisms in cell lines were examined by RT-PCR. M, 2000 marker. Lanes 1, OATP1B1 521TT was $260+179 \mathrm{bp} ; 2$, OATP1B1 388AA was $274 \mathrm{bp}$; 3, OATP1B1 388GG was $155+119$ bp; 4, OATP1B1 521CC was $260+123$ bp.

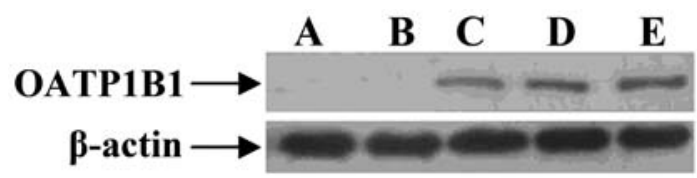

Figure 5. Western blotting of plasmid transfection. The OATP1B1 gene polymorphisms in cell lines were examined by western blot analysis. (A) MCF-7 cells; (B) pcDNA3.1(-) was transfected into MCF-7 cells; (C) pcDNA3.1 (-)-OATP1B1 was transfected into MCF-7 cells; (D) pcDNA3.1(-)-OATP1B1 388GG was transfected into MCF-7 cells; (E) pcDNA3.1(-)-OATP1B1 521CC was transfected into MCF-7 cells.

pcDNA3.1(-)-OATP1B1 521CC was transfected into MCF-7 cell. A and B did not express OATP1B1 protein, whereas C-E expressed OATP1B1 protein (Fig. 5).
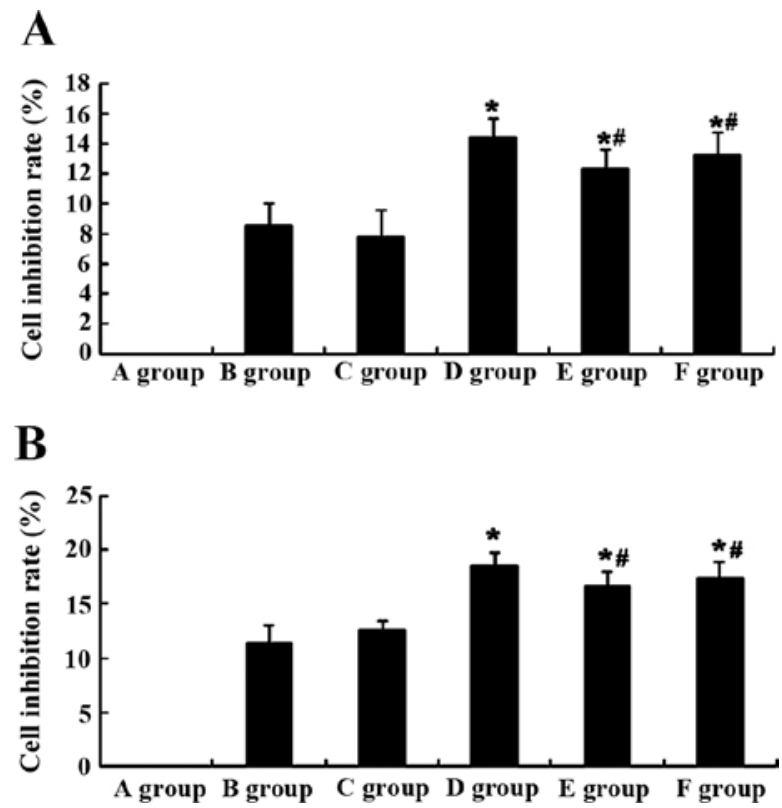

Figure 6. TAM effect on the cell inhibition rate of MCF-7 by plasmid transfection. Effect of TAM $(10 \mu \mathrm{M})$ on the inhibition rate of MCF-7 cells at (A) $24 \mathrm{~h}$ and (B) $48 \mathrm{~h} .{ }^{\text {"P }}<0.01$ compared with MCF-7 group, ${ }^{\text {"P }}>0.05$ compared with pcDNA3.1(-)-OATP1B1 transfected in the MCF-7 cell group. TAM, tamoxifen.

TAM effect on the cell inhibition rate of MCF-7 by plasmid transfection. We established expression platforms of OATP1B1 genetic polymorphisms to assess the role of OATP1B1 genetic polymorphisms of the effect of TAM $(10 \mu \mathrm{M})$ on the inhibition rate of MCF-7 cells. The results showed that at $24 \mathrm{~h}$, the inhibition rate of the D group was markedly increased $(\mathrm{P}<0.05, \mathrm{n}=3)$, compared to the $\mathrm{B}$ group (Fig. 6A). However, the inhibition rate of MCF-7 cells of the E and F 
A


B
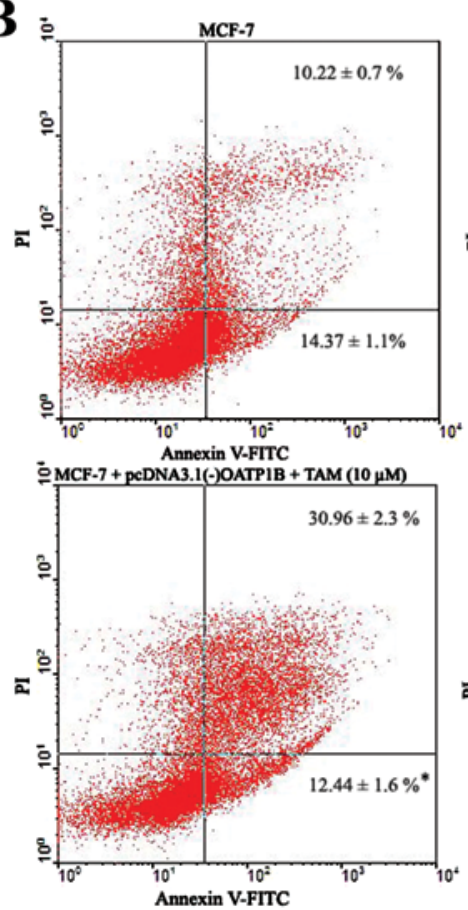
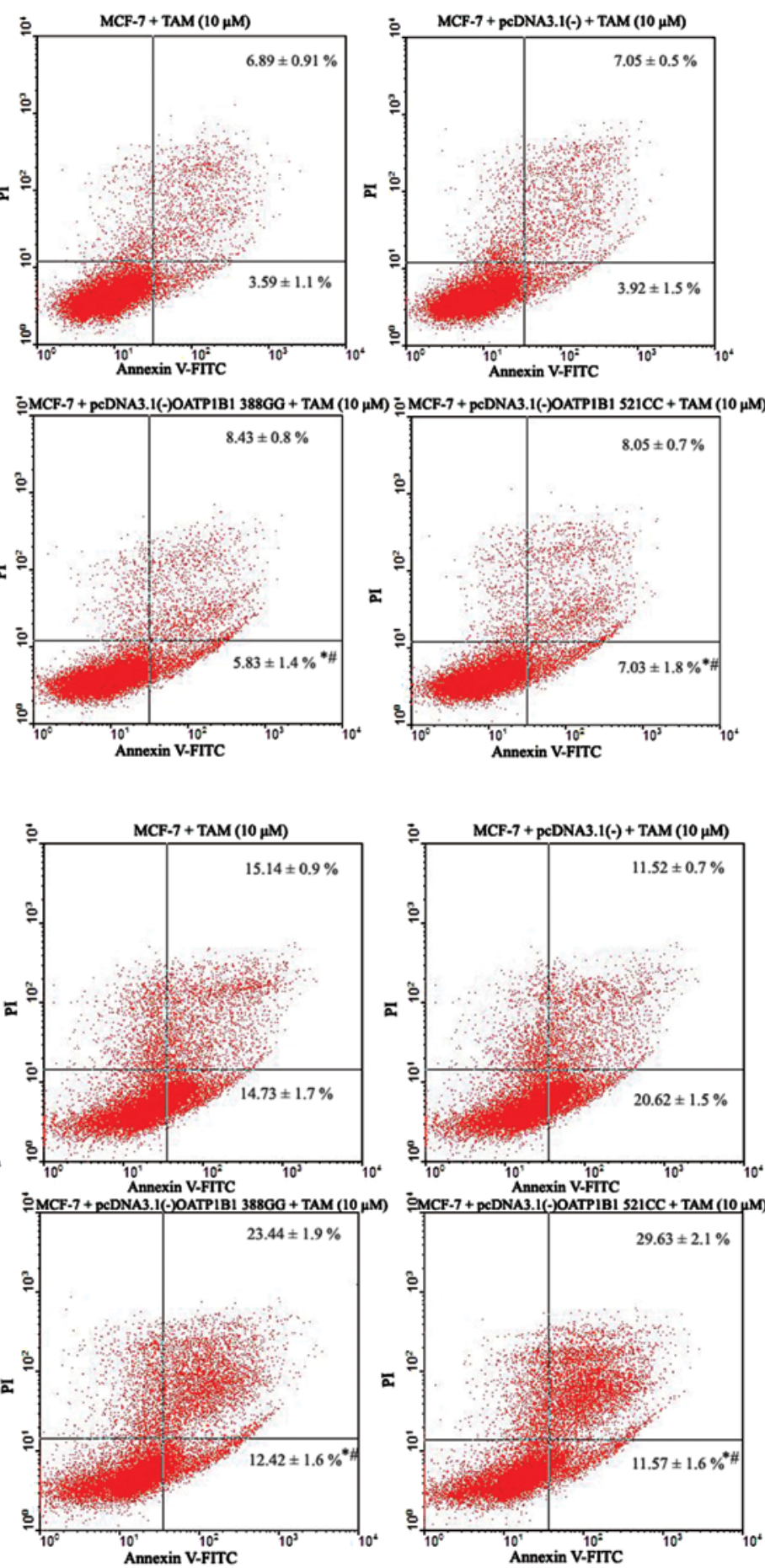

Figure 7. TAM effect on the cell apoptotic rate of MCF-7 by plasmid transfection. Effect of TAM $(10 \mu \mathrm{M})$ on the cell apoptotic rate of MCF-7 cells at (A) $24 \mathrm{~h}$ and (B) $48 \mathrm{~h} .{ }^{*} \mathrm{P}<0.01$ compared with MCF-7 group, ${ }^{~} \mathrm{P}>0.05$ compared with pcDNA3.1(-)-OATP1B1 transfected into MCF-7 cell group. TAM, tamoxifen.

groups was slightly decreased $(\mathrm{P}>0.05, \mathrm{n}=3)$ compared to the D group, although the difference was not statistically significant (Fig. 6A).

After the effect of TAM $(10 \mu \mathrm{M})$ on the proliferation of MCF-7 cells at $48 \mathrm{~h}$, the inhibition rate of $\mathrm{D}$ group was markedly increased $(\mathrm{P}<0.05, \mathrm{n}=3)$, compared to the $\mathrm{B}$ group (Fig. 6B). However, the inhibition rate of MCF-7 cells of the $\mathrm{E}$ and $\mathrm{F}$ groups were slightly decreased $(\mathrm{P}>0.05, \mathrm{n}=3$ ) compared to the $\mathrm{D}$ group, although the difference was not statistically significant (Fig. 6B).
TAM effect on the cell apoptotic rate of MCF-7 by plasmid transfection. We established expression platforms of OATP1B1 genetic polymorphisms to assess the role of OATP1B1 genetic polymorphisms on TAM $(10 \mu \mathrm{M})$ with regard to the apoptosis of MCF-7 cells. The results showed that at $24 \mathrm{~h}$, apoptosis in the $\mathrm{D}$ group was markedly increased $(\mathrm{P}<0.05, \mathrm{n}=3)$, compared to the B group (Fig. 7A and B). However, apoptosis of MCF-7 cells of the $\mathrm{E}$ and $\mathrm{F}$ groups was slightly decreased $(\mathrm{P}>0.05$, $\mathrm{n}=3$ ) compared to the $\mathrm{D}$ group, although the difference was not statistically significant (Fig. 7A and B). 

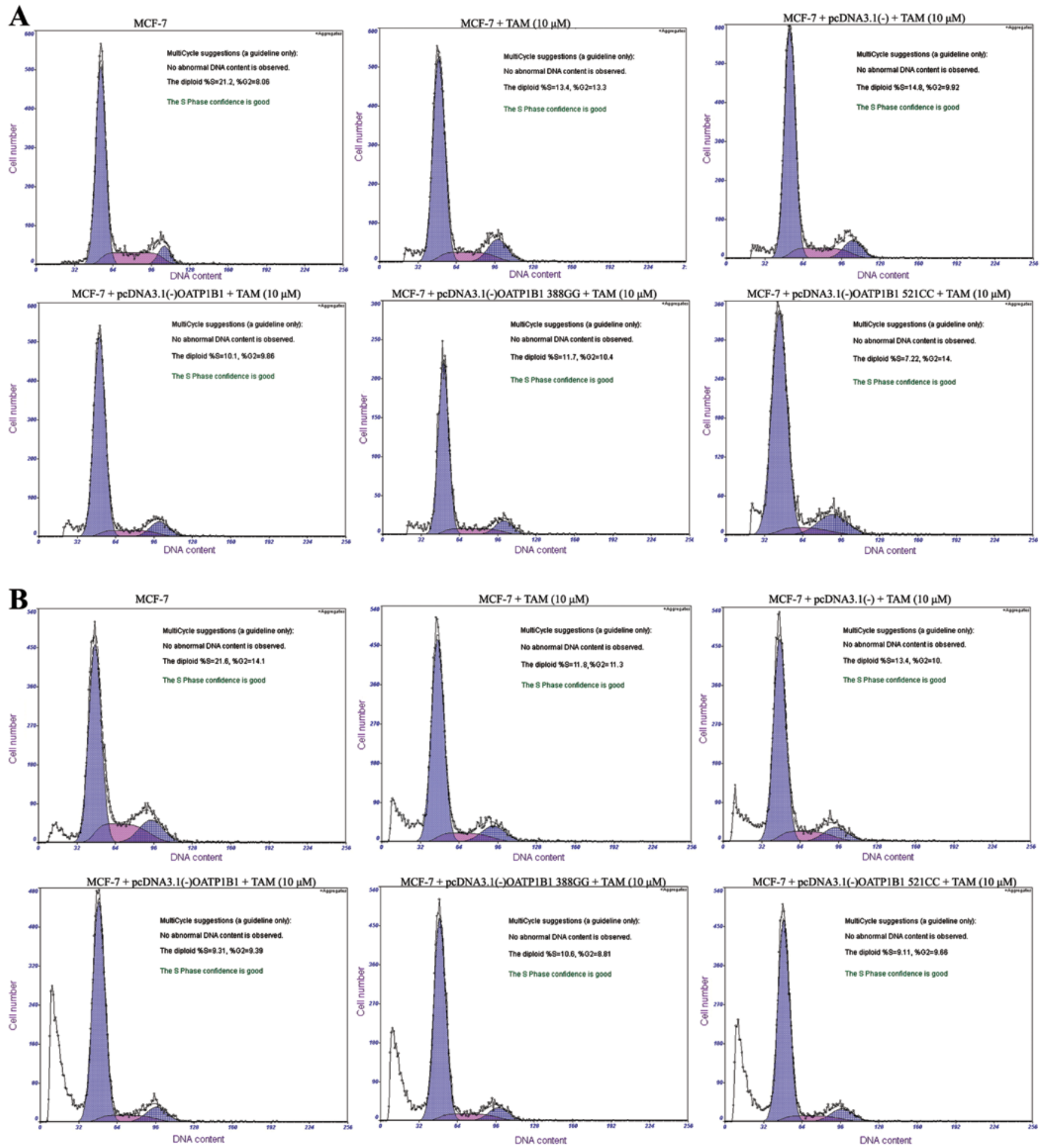

Figure 8. TAM effect on the cell cycle of MCF-7 by plasmid transfection. (A) Effect of TAM (10 $\mu \mathrm{M})$ on the cell cycle of MCF-7 cells at $24 \mathrm{~h}$ and (B) $48 \mathrm{~h}$. ${ }^{*} \mathrm{P}<0.01$ compared with MCF-7 group, ${ }^{\text {} P}>0.05$ compared with pcDNA3.1(-)-OATP1B1 transfected into the MCF-7 cell group. TAM, tamoxifen.

After the effect of TAM $(10 \mu \mathrm{M})$ on the apoptosis of MCF-7 cells at $48 \mathrm{~h}$, apoptosis of the $\mathrm{D}$ group was markedly increased $(\mathrm{P}<0.05, \mathrm{n}=3$ ), compared to the B group (Fig. 7C and D). However, the apoptosis of MCF-7 cells of the $\mathrm{E}$ and $\mathrm{F}$ groups was slightly decreased $(\mathrm{P}>0.05, \mathrm{n}=3)$ compared to the $\mathrm{D}$ group, although the differences were not statistically significant (Fig. 7C and D).

TAM effect on the cell cycle of MCF-7 by plasmid transfection. We established expression platforms of OATP1B1 genetic polymorphisms to assess the role of OATP1B1 genetic polymorphisms concerning the effect of TAM $(10 \mu \mathrm{M})$ on the cell cycle of MCF-7 cells. After the effect of TAM $(10 \mu \mathrm{M})$ on the cell cycle of MCF-7 cells at $24 \mathrm{~h}$, the $\mathrm{G}_{0} / \mathrm{G}_{1}$ phase in D group was markedly increased $(\mathrm{P}<0.05, \mathrm{n}=3)$, the $\mathrm{S}$ and $\mathrm{G}_{2} \mathrm{M}$ phases were markedly decreased $(\mathrm{P}<0.05, \mathrm{n}=3)$, compared to the $\mathrm{B}$ group (Table II, Fig. 8A). In $E$ and $F$ groups, the $G_{0} / G_{1}$ phase was slightly decreased $(P>0.05, n=3)$, while the $S$ and $G_{2} M$ phases were slightly increased $(P>0.05, n=3)$, respectively, compared 
Table II. TAM effect on the cell cycle of MCF-7 by plasmid transfection.

\begin{tabular}{lcrrrl}
\hline Time & \multirow{2}{*}{ Group } & $\mathrm{G}_{0} / \mathrm{G}_{1}(\%)$ & $\mathrm{S}(\%)$ & \multicolumn{1}{c}{$\mathrm{G}_{2} \mathrm{M}(\%)$} & PI-value \\
\hline $24 \mathrm{~h}$ & A & $68.71 \pm 3.12$ & $22.24 \pm 1.21$ & $5.78 \pm 1.02$ & 28.97 \\
& B & $74.33 \pm 2.24$ & $12.71 \pm 1.06$ & $12.84 \pm 1.01$ & 25.58 \\
& C & $74.79 \pm 2.31$ & $14.81 \pm 1.11$ & $9.92 \pm 1.03$ & 24.85 \\
& D & $79.57 \pm 1.69$ & $10.13 \pm 0.77$ & $9.86 \pm 0.59$ & $20.08^{\mathrm{a}}$ \\
& E & $77.76 \pm 1.78$ & $11.74 \pm 1.03$ & $10.4 \pm 1.00$ & $22.16^{\mathrm{a}, \mathrm{b}}$ \\
& F & $79.02 \pm 1.89$ & $6.88 \pm 0.98$ & $14.00 \pm 0.76$ & $20.90^{\mathrm{a}, \mathrm{b}}$ \\
& A & $64.32 \pm 3.53$ & $21.45 \pm 2.31$ & $13.93 \pm 2.13$ & 35.49 \\
& B & $75.90 \pm 2.72$ & $12.3 \pm 1.58$ & $11.06 \pm 1.35$ & 23.53 \\
& C & $76.63 \pm 2.69$ & $13.00 \pm 1.62$ & $10.33 \pm 1.40$ & 23.34 \\
& D & $81.21 \pm 2.09$ & $9.11 \pm 1.18$ & $9.66 \pm 1.21$ & $18.78^{\mathrm{a}}$ \\
& E & $80.15 \pm 2.11$ & $10.66 \pm 1.35$ & $8.81 \pm 1.25$ & $19.54^{\mathrm{a}, \mathrm{b}}$ \\
& F & $81.00 \pm 2.10$ & $9.31 \pm 1.20$ & $9.39 \pm 1.17$ & $18.76^{\mathrm{a}, \mathrm{b}}$ \\
& & & &
\end{tabular}

A group was MCF-7; B group was MCF-7 with TAM (10 $\mu \mathrm{M})$; C group was MCF-7 transfected with pcDNA3.1(-) plasmid with TAM $(10 \mu \mathrm{M})$; D group was MCF-7 transfected with pcDNA3.1(-)-OATP1B1 plasmid with TAM $(10 \mu \mathrm{M})$; E group was MCF-7 transfected with pcDNA3.1 (-)-OATP1B1 388GG plasmids with TAM $(10 \mu \mathrm{M})$; F group was MCF-7 transfected with pcDNA3.1(-)-OATP1B1 521CC plasmids with TAM $(10 \mu \mathrm{M}),{ }^{\mathrm{a}} \mathrm{P}<0.01$ compared with the MCF-7 group, ${ }^{\mathrm{b}} \mathrm{P}>0.05$ compared with pcDNA3.1(-)-OATP1B1 transfected into the MCF-7 cell group. TAM, tamoxifen.

to the $\mathrm{D}$ group, although the differences were not statistically significant (Table II, Fig. 8A).

After the effect of TAM $(10 \mu \mathrm{M})$ on the cell cycle of MCF-7 cells at $48 \mathrm{~h}$, the $\mathrm{G}_{0} / \mathrm{G}$ phase in the $\mathrm{D}$ group was markedly increased $(P<0.05, n=3)$, while the $S$ and $\mathrm{G}_{2} \mathrm{M}$ phases were markedly decreased $(\mathrm{P}<0.05, \mathrm{n}=3)$, compared to the $\mathrm{B}$ group (Table II, Fig. 8B). In the $E$ and $F$ groups, the $G_{0} / G_{1}$ phase was slightly decreased $\left(P>0.05, n=3\right.$ ), while the $S$ and $G_{2} M$ phases were slightly increased $(\mathrm{P}>0.05, \mathrm{n}=3)$, respectively, compared to $\mathrm{D}$ group, although the differences were not statistically significant (Table II, Fig. 8B).

\section{Discussion}

The functions of OATP1B1 are numerous, of which the specificity is distributed in the basolateral membrane of liver cells of the human. A variety of endogenous substances and drugs enter the liver cells via the portal system, including thyroid hormones, prostaglandin, bile acid, and statins. The OATPIBI gene is located on chromosome 12, with the full-length $10.86 \mathrm{~kb}$ (7). The encoding gene of SLCO1B1 includes 2,076 bases, encoding 691 amino acids, including 15 exons and 14 introns, as well as 20 function-genetic polymorphisms. The OATP1B1 gene has multiple single-nucleotide polymorphisms that are associated with abnormal uptake in in vitro or in vivo experiments, of which the OATPIBI gene $388 \mathrm{~A}>\mathrm{G}$ and 521T $>\mathrm{C}$ are the most common mutations (19). In a previous study, it was found that the $S L C O 1 B 1$ gene $388 \mathrm{~A}>\mathrm{G}$ polymorphism was not statistically significantly associated with gallstone formation in a north Indian population (20). SLCO1B1 $521 \mathrm{~T}>\mathrm{C}$ plays a significant role in susceptibility to colorectal cancer risk in the Turkish population (14). SLCO1B1 $388 \mathrm{~A}>\mathrm{G}$ and 521T $>\mathrm{C}$ polymorphisms were also not associated with response to atorvastatin or simvastatin (21).

In the present study, a molecular biology technique was applied to construct the pcDNA3.1(-)-OATP1B1 plasmid. The site-directed mutagenesis method was then used to establish pcDNA3.1(-)-OATP1B1 388GG and 521CC plasmids successfully. The pcDNA3.1(-)-OATP1B1-MCF-7 gene polypeptide expression platform demonstrated that OATP1B1 388GG and 521CC mutations lead to a decrease of the inhibition and apoptotic rate of breast cancer cells, compared to the OATP1B1 group, although the differences were not statistically significant.

Breast cancer cells in the $G_{0} / G_{1}$ phase were reduced in the OATP1B1 388GG and 521CC groups, compared to the OATP1B1 group. Breast cancer cells in the $\mathrm{S}$ and $\mathrm{G}_{2} \mathrm{M}$ phases were increased in the OATP1B1 388GG and 521CC groups, compared to the OATP1B1 group, although the differences were not statistically significant. Therefore, pre-synthesis DNA of breast cancer cells in the OATP1B1 388GG and 521CC group were reduced, while DNA increased in the synthesis and post-synthesis phase, causing the decreased inhibition rate of MCF-7 cells, thereby reducing the effect of TAM on MCF-7 cells. This conclusion is consistent with the inhibition rate and apoptosis results.

In summary, our present investigation has shown that OATP1B1 388GG and 521CC mutations may inhibit the activity of the OATP1B1 protein. OATP1B1 388GG and 521CC mutations may lead to restraining of the turn-over capacity of OATP1B1 and a reduction of TAM that is internalized into MCF-7 cells, resulting in weakened TAM treatment for breast cancer.

Nozawa et al (22) and Iwai et al (23) employed HEK293 cells and used estrone sulfate and estradiol-17 $\beta$-glucuronide as a substrate, finding OATP1B1 $388 \mathrm{GG}$ and 521CC had no significant effect on OATP1B1 absorbing ability, consistent with the results of the present study. OATP1B1 388GG and 521CC mutations cause decreased capacity of OATP1B1 in absorbing TAM, without statistical significance compared with the gene groups that have not mutated. This occurs due to OATP1B1 388GG and 521CC mutations being single mutation sites, and these changes of the DNA sequence result in such limited change of the protein structure and composition of OATP1B1 protein that effective change for the turn-over capacity cannot be markedly inhibited. This phenomenon is extremely common in gene mutations. The results of that study found that CYP2D6*4 or *10 mutations have a limited impact on the efficacy of TAM, and the difference was not statistically significant (24). Previous findings have shown that CYP2C19*2 and $* 3$ mutations have limited impact on the efficacy of TAM, and the difference was not statistically significant (25).

The ability of SLCO1B1*15 (388G/521C) in absorbing estrone sulfate and estradiol-17 $\beta$-glucuronide was found to be significantly reduced (26), indicating that the double mutation (SLCO1B1*15) may have greater significance on the transport of TAM. In summary, 388GG and 521CC of OATP1B1 gene polymorphism expression platforms were established in this experiment. The results show that 
OATP1B1 388GG and 521CC mutations lead to the decreased turn-over capacity of OATP1B1 and a reduction of TAM in the treatment of breast cancer, although the difference was not statistically significant. Thus construction of a OATP1B1*15 double mutation plasmid to study the changes in drug absorption should be carried out in future investigations.

\section{Acknowledgements}

This study was supported by the Key Clinical Medicine Application Technology Item of Anhui Provincial Health Department (no. 2010A013), and the Natural Science Foundation of China (grant no. 81173134).

\section{References}

1. Knaul FM, Bhadelia A, Gralow J, et al: Meeting the emerging challenge of breast and cervical cancer in low- and middleincome countries. Int J Gynaecol Obstet 119 (Suppl 1): S85-S88, 2012.

2. Harbeck N: American Society of Clinical Oncology highlights 2013: breast cancer and gynecological malignancies. Future Oncol 9: 1433-1436, 2013.

3. Karaoz B, Aksu H and Küçïk M: A qualitative study of the information needs of premenopausal women with breast cancer in terms of contraception, sexuality, early menopause, and fertility. Int J Gynaecol Obstet 109: 118-120, 2010.

4. Kattan J and Kourie HR: The use of everolimus to reverse tamoxifen resistance in men with metastatic breast cancer: a case report. Invest New Drugs 32: 1046-1047, 2014.

5. Yaacob NS, Kamal NN and Norazmi MN: Synergistic anticancer effects of a bioactive subfraction of Strobilanthes crispus and tamoxifen on MCF-7 and MDA-MB-231 human breast cancer cell lines. BMC Complement Altern Med 14: 252, 2014.

6. Alcazar-González GA, Calderón-Garcidueñas AL, GarzaRodríguez ML, et al: Comparative study of polymorphism frequencies of the CYP2D6,CYP3A5, CYP2C 8 and $I L-10$ genes in Mexican and Spanish women with breast cancer. Pharmacogenomics 14: 1583-1592, 2013.

7. Hsiang B, Zhu Y, Wang Z, et al: A novel human hepatic organic anion transporting polypeptide (OATP2). Identification of a liver-specific human organic anion transporting polypeptide and identification of rat and human hydroxymethylglutaryl-CoA reductase inhibitor transporters. J Biol Chem 274: 37161-37168, 1999.

8. Niemi M, Schaeffeler E, Lang T, et al: High plasma pravastatin concentrations are associated with single nucleotide polymorphisms and haplotypes of organic anion transporting polypeptide-C (OATP-C, SLCO1B1). Pharmacogenetics 14: 429-440, 2004

9. Mwinyi J, Johne A, Bauer S, et al: Evidence for inverse effects of OATP-C (SLC21A6) *5 and *1b haplotypes on pravastatin kinetics. Clin Pharmacol Ther 75: 415-421, 2004.

10. Niemi M, Neuvonen PJ, Hofmann U, et al: Acute effects of pravastatin on cholesterol synthesis are associated with SLCO1B1 (encoding OATP1B1) haplotype *17. Pharmacogenet Genomics 15: 303-309, 2005
11. Igel M, Arnold KA, Niemi M, et al: Impact of the SLCO1B1 polymorphism on the pharmacokinetics and lipid-lowering efficacy of multiple-dose pravastatin. Clin Pharmacol Ther 79: 419-426, 2006.

12. Chung JY, Cho JY, Yu KS, et al: Effect of OATP1B1 (SLCO1B1) variant alleles on the pharmacokinetics of pitavastatin in healthy volunteers. Clin Pharmacol Ther 78: 342-350, 2005.

13. Ieiri I, Suwannakul S, Maeda K, et al: SLCO1B1 (OATP1B1, an uptake transporter) and ABCG2 (BCRP, an efflux transporter) variant alleles and pharmacokinetics of pitavastatin in healthy volunteers. Clin Pharmacol Ther 82: 541-547, 2007.

14. Ozhan G, Kara M, Sari FM, et al: Influence of the functional polymorphisms in the organic anion transporting polypeptide 1B1 in the susceptibility to colorectal cancer. Genet Test Mol Biomarkers 17: 214-218, 2013.

15. D'Avolio A, Carcieri C, Cusato J, et al: Intracellular accumulation of atazanavir/ritonavir according to plasma concentrations and $O A T P 1 B 1, A B C B 1$ and $P X R$ genetic polymorphisms. J Antimicrob Chemother 69: 3061-3066, 2014.

16. Hua WJ, Hua WX, Nan FY, et al: The influence of herbal medicine ursolic acid on the uptake of rosuvastatin mediated by OATP1B1*1a and *5. Eur J Drug Metab Pharmacokinet 39: 221-230, 2014.

17. Rose RH, Neuhoff S, Abduljalil K, et al: Application of a physiologically based pharmacokinetic model to predict OATP1B1-related variability in pharmacodynamics of rosuvastatin. CPT Pharmacometrics Syst Pharmacol 3: e124, 2014.

18. Rohrbacher M, Kirchhof A, Skarke C, et al: Rapid identification of three functionally relevant polymorphisms in the OATP1BI transporter gene using Pyrosequencing ${ }^{\mathrm{TM}}$. Pharmacogenomics 7: 167-176, 2006.

19. Nishizato Y, Ieiri I, Suzuki H, et al: Polymorphisms of OATP-C (SLC21A6) and OAT3 (SLC22A8) genes: consequences for pravastatin pharmacokinetics. Clin Pharmacol Ther 73: 554-565, 2003.

20. Jindal C, Kumar S, Choudhari G, et al: Organic anion transporter protein (OATP1B1) encoded by SLCO1B1 gene polymorphism $(388 \mathrm{~A}>\mathrm{G}) \&$ susceptibility in gallstone disease. Indian J Med Res 129: 170-175, 2009.

21. Giannakopoulou E, Ragia G, Kolovou V, et al: No impact of SLCO1B1 521T $>\mathrm{C}, 388 \mathrm{~A}>\mathrm{G}$ and $411 \mathrm{G}>\mathrm{A}$ polymorphisms on response to statin therapy in the Greek population. Mol Biol Rep 41: 4631-4638, 2014.

22. Nozawa T, Nakajima M, Tamai I, et al: Genetic polymorphisms of human organic anion transporters OATP-C (SLC21A6) and OATP-B (SLC21A9): allele frequencies in the Japanese population and functional analysis. J Pharmacol Exp Ther 302: 804-813, 2002.

23. Iwai M, Suzuki H, Ieiri I, et al: Functional analysis of single nucleotide polymorphisms of hepatic organic anion transporter OATP1B1 (OATP-C). Pharmacogenetics 14: 749-757, 2004.

24. Sirachainan E, Jaruhathai S, Trachu N, et al: CYP2D6 polymorphisms influence the efficacy of adjuvant tamoxifen in Thai breast cancer patients. Pharmgenomics Pers Med 5: 149-153, 2012.

25. Okishiro M, Taguchi T, Jin Kim S, et al: Genetic polymorphisms of CYP2D6*10 and CYP2C19*2, $* 3$ are not associated with prognosis, endometrial thickness, or bone mineral density in Japanese breast cancer patients treated with adjuvant tamoxifen. Cancer 115: 952-961, 2009.

26. Tirona RG, Leake BF, Merino G and Kim RB: Polymorphisms in $O A T P-C$ : identification of multiple allelic variants associated with altered transport activity among European- and AfricanAmericans. J Biol Chem 276: 35669-35675, 2001. 